$$
\begin{array}{cc}
\text { CONF-970210-5 } \\
\text { ANL/ES/CP.-92018 RFP MVIVD } \\
\text { MAR 251997 } \\
\text { OSTI }
\end{array}
$$

\title{
Lifecycle Analysis for Automobiles: Uses and Limitations
}

\author{
Linda Gaines and Frank Stodolsky \\ Argonne National Laboratory \\ Argonne, Illinois
}

for presentation to

1997 SAE International Congress \& Exposition

Cobo Center, Detroit, Michigan

February 24-27, 1997

DISTRIBUTION OF THIS DOCUMENT IS UMLUMTEED

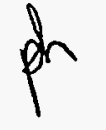

sponsored by Society of Automotive Engineers International (SAE) Warrendale, Pennsylvania

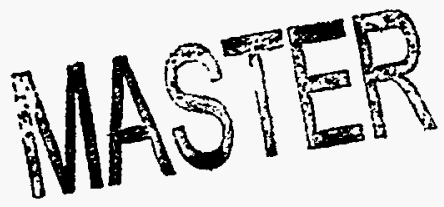

The submitted manuscript has been created by the University of Chicago as Operator of Argonne

National Laboralory ("Argonne") under Contract

No. W-31-109-ENG-38 with the U.S.

Department of Energy. The U.S. Government retains for itself. and others acting on its behalf, a paid-up, nonexclusive, imevocable woridwide license in said article to reproduce, prepare derivative works, distribute copies to the public, and perform publicly and display publicly, by or on behalf of the Government. 


\title{
Lifecycle Analysis for Automobiles: Uses and Limitations
}

\author{
Linda Gaines and Frank Stodolsky \\ Argonne National Laboratory
}

\begin{abstract}
There has been a recent trend toward the use of lifecycle analysis (LCA) as a decision-making tool for the automotive industry. However, the different practitioners' methods and assumptions vary widely, as do the interpretations put on the results. The lack of uniformity has been addressed by such groups as the Society of Environmental Toxicology and Chemistry (SETAC) and the International Organization for Standardization (ISO), but standardization of methodology assures neither meaningful results nor appropriate use of the results. This paper examines the types of analysis that are possible for automobiles, explains possible pitfalls to be avoided, and suggests ways that LCA can be used as part of a rational decision-making procedure.

The key to performing a useful analysis is identification of the factors that will actually be used in making the decision. It makes no sense to analyze system energy use in detail if direct financial cost is to be the decision criterion. Criteria may depend on who is making the decision (consumer, producer, regulator). LCA can be used to track system performance for a variety of criteria, including emissions, energy use, and monetary costs, and these can have spatial and temporal distributions. Because optimization of one parameter is likely to worsen another, identification of trade-offs is an important function of LCA.
\end{abstract}

\section{INTRODUCTION}

Lifecycle analysis (LCA) is a powerful tool, often used as an aid to decision making in the automotive industry. LCA forms the foundation of the newly-invented field of industrial ecology. There are several possible uses and users for this tool. It can be used to evaluate the impacts from a process or from production and use of a product. Impacts from competing products or processes can be compared to help manufacturers or consumers choose among options, including foregoing the service the product or process would have provided because the impacts are too great. Information about impacts can be used by governments to set regulations, taxes, or tariffs; to allocate funds for research and development (R\&D) or low-interest loans; or to identify projects worthy to receive tax credits. In addition, LCA can identify key process steps and, most important, key areas where process changes, perhaps enabled by R\&D, could significantly reduce impacts. Analysts can use the results to help characterize the ramifications of possible policy options or technological changes.

The basic procedure is, in concept, relatively straightforward. Examine the entire system, evaluate the impacts, and choose the best option. But in actual practice, there are a number of difficulties. Each of the key words used in describing the procedure needs careful definition, or the results obtained may be different. The system must be defined so that the entire lifecycle is included, or important effects may be neglected. Alternatively, smaller systems with equivalent inputs and output can be compared. The impacts of concern must be identified, and these can range from a single air emission (e.g., $\mathrm{CO}_{2}$ ) to total financial costs. Impacts may be difficult to evaluate, and they may be regional or global, as well as distributed in time. The analyst or decision-maker must finally decide what is meant by "best." If there are trade-offs among impacts, how should they be weighted? Different weightings might imply different decisions.

The procedures for performing the inventory part of a lifecycle analysis (but not the impact analysis) have been very well defined by such groups as the Society of Environmental Toxicology and Chemistry (SETAC) and the International Organization for Standardization (ISO), and adherence to the standard methodology makes it easier for anyone to do such an analysis. That is both good and bad. It eliminates certain common types of errors and assures at least minimal consistency among studies. But it also imparts credibility to anyone adhering to the standard procedure, while still leaving several potential pitfalls that even reputable and experienced analysts can fall into. This paper describes LCA concepts, provides examples from automotive-related LCAs of pitfalls, and illustrates ways to avoid them.

\section{LCA CONCEPTS,$\ldots$}

This section briefly describes our concept of LCA. LCA is an effective tool when a decision must be made about how to deal with a specific, limited problem. (For some purposes, larger problems can be tackled, but these and the associated institutional issues are very complicated.). The logical steps in the LCA procedure are described below. 


\section{DISCLAIMER}

This report was prepared as an account of work sponsored by an agency of the United States Government. Neither the United States Government nor any agency thereof, nor any of their employees, make any warranty, express or implied, or assumes any legal liability or responsibility for the accuracy, completeness, or usefulness of any information, apparatus, product, or process disclosed, or represents that its use would not infringe privately owned rights. Reference herein to any specific commercial product, process, or service by trade name, trademark, manufacturer, or otherwise does not necessarily constitute or imply its endorsement, recommendation, or favoring by the United States Government or any agency thereof. The views and opinions of authors expressed herein do not necessarily state or reflect those of the United States Government or any agency thereof. 
SYSTEM DEFINITION-The first step in a complete LCA is to determine what consumers actually require. They do not usually require a specific product made from a specific material, hut rather a service that will meet their primary needs (such as (ransportation). Once the actual requirements are identified, the next step is to define all of the possible means to satisfy them (such as using a different process to produce the product or recycling it). All of the inputs and outputs associated with each option-must be identified; care must be taken to ensure that systems to be compared have equivalent functionality.

PROCESS ANALYSIS-The next step in the analysis is to actually inventory all of the process inputs and outputs for every element of the system and for each process or product option. The collection and interpretation of data are nontrivial activities and the subject of a considerable volume of literature. We employed flowcharts to aid in our understanding of energy and material flows in industrial processes (inputs and outputs, including residuals). An example is provided in Figure 1. It is important to allocate inventory items among co-products correctly (the convention of allocation on a weight basis may not always be appropriate). Care must also be taken to distinguish between data based on all production facilities (average) and those from new (marginal) capacity, because the latter are often more relevant for decisions about future production. It is also important to retain information about geographical and temporal distributions of the inventory items.

Once the data are assembled, the inventory items are added up to provide a total profile for each option. In many LCAs, the inventory is the final product. However, even though it is very difficult to do an impact analysis (the next step in the standard SETAC methodology), the inventory can provide useful information to aid decision makers.

CRITERIA CHOICE-The analyst must then determine the goals to be accomplished (i.e., define the criteria to be used for choosing the best option). The choice of criteria is a policy decision; the criteria should be explicit, rather than vague "motherhood and apple pie" justifications like conserving resources. Which resources do we want to conserve? Possibilities include energy in general, fossil fuels, trees, landfill space, and clean air. Other possible goals include minimizing costs, either for production or over the product's life cycle. But any decision (including changes in lifestyle that would reduce or eliminate the demand) involves trade-offs. It is often difficult to conserve one resource without using more of another. So priorities must be more detailed, and may differ, depending on who is setting the policy and where the decision is being made.

Minimizing the total cost to society might be considered the ultimate criterion for a product or process choice. The total social cost includes the direct financial cost and indirect costs. Indirect costs, which differ for virgin and recycled products, are generally not reflected in the market price of the products. Indirect costs can result from impacts on unpriced resources (such externalities as air and water quality, wilderness, parks, and wildlife habitats), as well as costs to other parties (such as damage to buildings from acid rain). External costs are sometimes internalized by the government through regulations, such as limits on $\mathrm{SO}_{2}$ emissions from utilities and industrial boilers. Another social cost that may not be adequately reflected in the market price is the time-related value of resources. For example, the current market price of petroleum may not reflect potential future economic scarcity. In addition, there may be strategic considerations, such as the value of having a domestic supply or the costs of ensuring that imports remain uninterrupted.

Full-cost accounting is a tool that attempts to assign values to all of the costs to society, but it is very difficult to implement properly. An ideal procedure would begin with all of the lifecycle process inventories and then estimate their impacts (e.g., health and environmental), including long-term effects. Such an estimate is extremely difficult to make and has never actually been done. The next, even more difficult step, would be to quantify the relative costs (in terms of a single parameter like dollars) of the different impacts. Not only would this require a complex comparison (for example, a comparison of the costs to society from acid rain damage to forests in one region with the health effects from lead inhalation in another region), but it would also require a determination of the appropriate discount rates for future costs. These are extremely thorny issues, and societal consensus is unlikely. Therefore, this decision criterion, although perhaps ideal conceptually, is impractical to implement.

Real decision makers must use simpler criteria, such as minimizing petroleum usage or greenhouse gas emissions, that are easier to evaluate because they. result directly from the inventory. The options can be evaluated in terms of the chosen decision criteria, the trade-offs can be identified, and then the implications for policy can be clarified. The preferred option best optimizes decision criteria; therefore, criteria should be carefully defined and meaningful because they will determine the decision. Results may also differ depending on the location being studied. There is no standard procedure for interpreting results. Many studies we reviewed fail to draw useful conclusions from the information gathered, even if the data were collected and presented in a competent manner. The studies we discuss are intended as examples only. Therefore, we do not provide precise citations.

\section{EXAMPLES}

The automotive LCA examples presented below illustrate such pitfalls as unclear system definition, inaccurate process analysis, and imprecise criterion definition. We identify shortcomings in these analyses and then suggest ways to improve them.

ENERGY ANALYSES-The example concerns possible energy savings from use of lightweight materials, such as aluminum, in the bodies of future automobiles. It illustrates the effect of misapplication of the three logical steps in the LCA process. It is a fairly straightforward task to tabulate the energy requirements for all of the automobile materials and come up with total production energies for the conventional and lightened vehicles, given the weights of the components in which the material substitution has taken place. If virgin aluminum, which is very energy-intensive, is replacing steel, the total energy used for production of the lightweight vehicle is likely to be greater than that for the conventional vehicle. The fuel savings over the lightweight vehicle's operation can be computed and compared to the production energy penalty to determine lifecycle energy savings, if any. Several recent studies that have done just that have found that the energy penalty is not paid off until the vehicle has traveled $100,000 \mathrm{~km}$ or more. Their conclusion is that use of lightweight materials results in only minimal lifetime energy savings, and therefore should not be given high priority. 


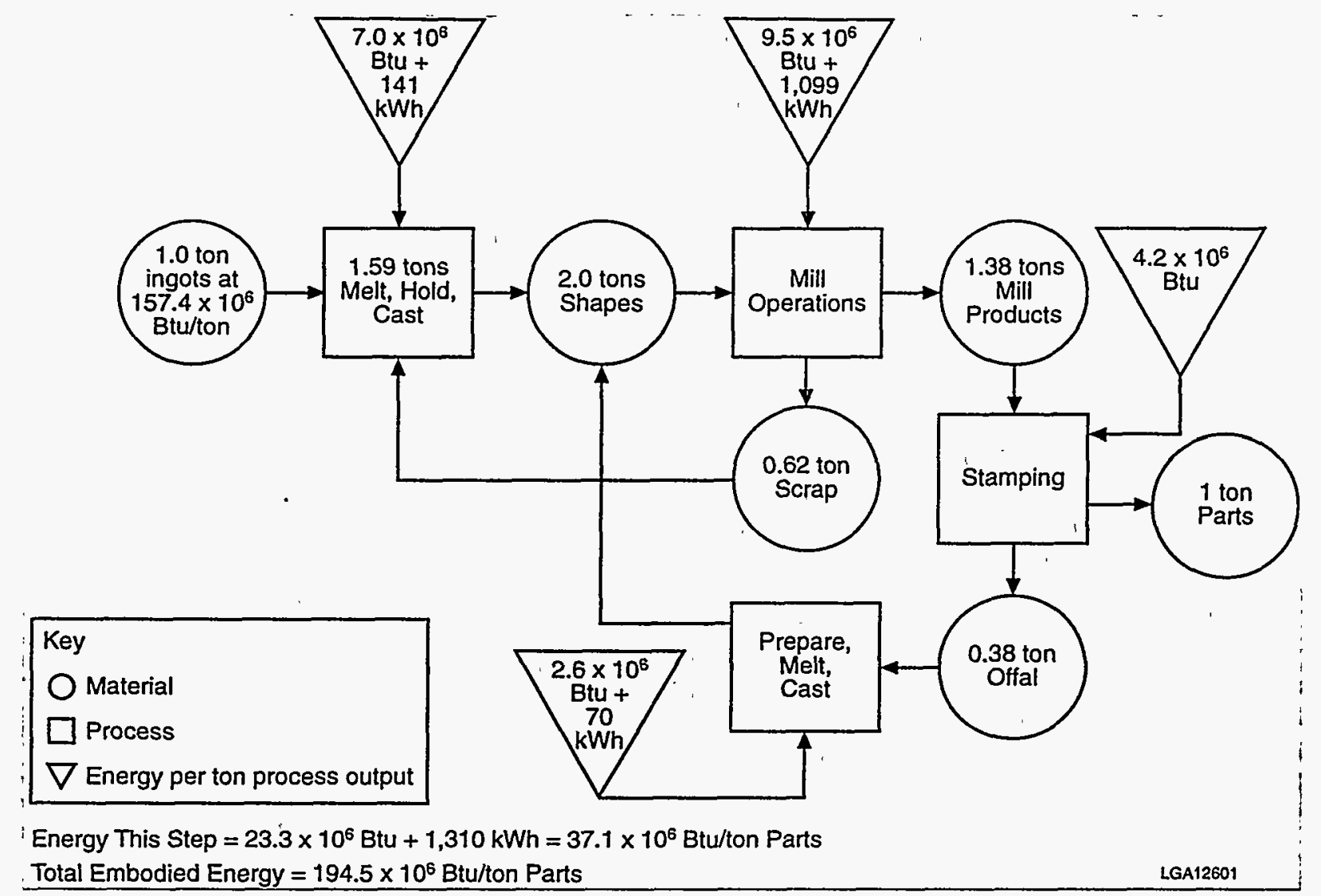

Figure 1: Stamped Aluminum Part Production from Ingots

However, these studies make several errors. The first error is failing to recognize that, even if lifecycle energy use is not reduced by substitution of lightweight materials, dependence on petroleum is definitely reduced, and this may be a key cost and national security concern (imprecise criterion definition). The second error is simply neglecting the secondary weight savings enabled by using lighter components. Secondary weight savings accrue as a result of redesigning other components to take advantage of the lighter vehicle body. These savings reduce production energy and further reduce gasoline consumption (technical detail not covered in standard methodology). Correction of this error results in reduction of the break-even mileage. The third error is the use of virgin aluminum in the energy calculation (incomplete set of systems analyzed). Some of the aluminum currently used in cars is cast and some is wrought (sheet and extrusions). The cast aluminum is already largely recycled, but the wrought aluminum is generally virgin, because all the aluminum currently recovered from cars goes into cast products. No credit is given for energy recovered from recycling the recovered wrought products to cast products (or in some cases, even from recovered cast products) in the faulty studies, and no thought is given to the obvious solution. In the future, if large quantities of wrought aluminum are used in cars, the material will be recycled, drastically reducing the energy requirements for aluminum auto parts.

Results from lifecycle analysis in which secondary weight savings and recycling of wrought aluminum are considered are shown in Table 1. Petroleum is saved, and the overall lifecycle energy benefit from substitution of aluminum for steel is positive. In addition, the initial production energy of the lighter vehicle (in which some of the wrought material is recycled) may be lower than that of theconventional vehicle. The useful conclusion then is that substitution by lightweight materials can indeed save energy. R\&D should therefore be directed at enabling the use of recycled materials; this may include further studies of alloy compatibility and disassembly techniques.

ENVIRONMENTAL ANALYSES-This section illustrates pitfalls in studies that focus on life-cycle environmental impacts. Two examples concern electric vehicles (EVs), and one example concerns auto painting.

Electric Vehicles-Currently, EVs have popular appeal because they are "zero-emission vehicles" (i.e., there are no tailpipe emissions at the vehicle's point of use). This is a considerable advantage in heavily polluted urban areas. However, there is a price to pay for clean operation. There are impacts from the electricity generation, and there are additional impacts from the production and recycling of the batteries (to a first approximation, the rest-of-the-vehicle is the same for electric and conventional vehicles). These impacts generally occur in different locations than where the vehicle operates, and so trade-offs are not only among impacts, but among their recipients. For instance, use of EVs in the Los Angeles (LA) basin would improve air quality ${ }^{1}$ for that area's large population at the expense of air quality out-of-basin. For instance, some of

1 In terms of nitrogen oxides $\left(\mathrm{NO}_{\mathrm{x}}\right)$, volatile organic compounds (VOCs), carbon monoxide (CO), total suspended particulates (TSP), sulfur oxides $\left(\mathrm{SO}_{\mathrm{x}}\right)$, and carbon dioxide $\left(\mathrm{CO}_{2}\right)$. 
Table 1. Mid-Sized Vehicle Lifecycle Primary Energy Requirements [Source: Ref.I]

\begin{tabular}{lcccc}
\hline \multicolumn{1}{c}{ Energy (GJ/car)* } & Conventional & Lightweight & Conventional Recycled** & Lightweight Recycled** $^{*}$ \\
\hline & & & & \\
Vehicle Production & 104 & 107 & 79 & 66 \\
Lifetime Fuel Use & 867 & 759 & 867 & 759 \\
Total Lifecycle Energy & 971 & 866 & 946 & 825 \\
\hline
\end{tabular}

* To convert to million Btu/car, multiply by 0.949 .

** Assumes recycled content of at least $90 \%$ for metals.

LA's electricity comes from Four Corners, where the exposed population is lower, so human impacts are lower, but there is an equity issue. Should the people in the Four Corners area breathe less pure air to benefit those in LA? And there is an additional impact: visibility over the Grand Canyon. Is cleaner air in LA worth a decrease in visibility at the Grand Canyon? In the east, the analysis is simpler because most power generation is in-basin, so, unless the power is nuclear, the local air quality benefits of EV use may be small. The Electric Vehicle Total Energy Cycle Analysis (EVTECA) project, currently being concluded by several national laboratories, will provide more details on the trade-offs for four U.S. metropolitan areas.

The second example is based on an analysis of emissions from manufacturing and recycling of lead-acid batteries for EVs. It is useful to show that battery manufacture and recycling can be the source of significant lead pollution, but the data used in one study were seriously flawed. The results were based on old data (including emissions before EPA regulation of the industry), and no other emissions from the entire vehicle lifecycle were considered. In addition, the study failed to note that (most of) the lead emissions occurred outside of the populated urban areas where the vehicles were to operate, thus accomplishing the primary goal of EV use, in trade for other impacts. The published conclusion was that EVs should be dismissed from further consideration. A more appropriate conclusion is that EVs with oversized lead-acid batteries manufactured without current emission controls would cause significant out-of-basin impacts. Results of more careful analysis identify trade-offs among impacts and let policy-makers draw their own conclusions. For instance, we find that, because manufacture of virgin nickel for $\mathrm{NiMH}$ or $\mathrm{NiCd}$ batteries produces significant $\mathrm{SO}_{2}$ emissions, use of these battery types would require closed-loop recycling of the $\mathrm{Ni}$ electrodes to minimize these emissions [2]. Note also that $\mathrm{Ni}$ for electrodes is all imported, so those emissions are not only out-of-basin, but out of the country.

Auto Painting-This example, concerning environmental implications of auto body painting, illustrates problems encountered when vague "motherhood and apple pie" justifications are used to determine the criteria and the system is not adequately defined at the outset of the analysis. The goal of the study was to identify ways to improve the "eco-efficiency" of auto manufacturing. However, the term "eco-efficiency" was not clearly defined. While pollution prevention, waste reduction, and product stewardship were identified as keys to achieving ecoefficiency, neither their meanings nor acceptable trade-offs among them were made clear. For example, use of a highly toxic but effective paint solvent, required in smaller quantities than the standard solvent, would result in less waste as paint sludge (waste reduction), but it would increase the toxicity of air emissions, perhaps making the new solvent an unacceptable option.

In addition, the system to be studied was not carefully defined. The initial study focus was on auto painting options (at the assembly plant level), and excellent emissions and energy data were obtained for one plant. In the name of product stewardship (the product was not defined), the system boundary was broadened to include raw material extraction, auto use, and final disposition, including the effect of substitution of aluminum and polymers for steel in body panels. The researchers found comparable VOC emissions and paint sludge generation from painting an "all-steel"- or an "all-aluminum"- bodied car. ${ }^{2}$ They also found that tailpipe emissions of $\mathrm{CO}_{2}$ and other criteria pollutants during vehicle operation were significantly greater than those from auto painting or from substrate manufacture. And operation of the lighter, aluminum-bodied car produced lower emissions than operation of the steel-bodied car.

Further, the aluminum-bodied car was found to save more energy (as petroleum) than the steel-bodied car if the aluminum was recycled and chassis components were downsized. If the criterion was life-cycle energy, the aluminum vehicle would be the preferred option, regardless of the painting technology used. However, the decision to produce aluminum vehicles is beyond the control of the auto painting operation. While lifecycle energyand emissions characteristics of the substrate material dominate the outcome, less-than-complete data were available on the substrate material. Therefore, what began as the development of a comprehensive assessment of painting emissions and energy use at the plant level ended up as a relatively poor assessment of steel- vs. aluminum-bodied vehicles. In this case, a more appropriate system boundary would have been simply the painting process. That way, the researchers could have focused on the operations they could control and understood well, like minimization of emissions at a particular plant. A broader focus would be appropriate for a public policy decision on resource use, but not for optimizing the painting process.

2 However, the sludge from aluminum painting is defined by the EPA as hazardous, but that from steel painting is defined as nonhazardous. 


\section{USE OF LCA IN DECISION MAKING}

In a free-market society, decisions are not made by a central planning organization that optimizes the total social costs or the criteria the society chooses for itself, but on the basis of market prices of alternative products. These are, in turn, based only on the direct financial costs incurred by their producers, including the price of purchased resources used (materials, energy, labor), capital investments, profit taken, and any costs imposed by government action (these may be negative). Costs differ by location, both domestically and internationally.

The United States does not have a totally free market economy; numerous government actions can change the direct costs to producers to either encourage or discourage the use of one product or process relative to another. Examples of such actions include subsidies, depletion allowances, targeted or low-interest loans, varying interest rates, research and development support, mandates, and regulations. Some of these actions, such as mandates for purchasing recycled products, may influence decisions regardless of cost. Producers and advocacy groups can also influence the public's perceptions of a product's true costs and benefits. Through selective education and advertising, they can change the public's preferences (changing the demand and, in turn, the price). Producers can also adjust the relative prices of the different products they sell. If the market does not naturally lead to the best solution identified by LCA on the basis of selected criteria, the government, industry, and public interest groups can use any of these actions to influence the situation in favor of that solution.

\section{ACKNOWLEDGMENTS}

This work was supported by the U.S. Department of Energy, Assistant Secretary for Energy Efficiency and Renewable Energy, under contract W-31-109-Eng-38.

\section{REFERENCES}

1. Stodolsky, F., et al. Life Cycle Energy Savings Potential from Aluminum-Intensive Vehicles, Society of Automotive Engineers, Paper 951837, Warrendale, Penn., 1995.

2. Gaines, L., and M. Singh, Energy and Environmental Impacts of Electric Vehicle Battery Production and Recycling, Society of Automotive Engineers, Paper 951865, Warrendale, Penn., 1995. 